\title{
Von Hippel-Lindau's Disease
}

\author{
ROBERT G. MILLER, ROGER J. PORTER, SURL L. NIELSEN, AND HOSHIO HOSOBUCHI
}

SUMMARY: A patient with Von HippelLindau's disease was followed from the time of diagnosis to the time of his death 13 years later. He was asymptomatic when the diagnosis was made, although a hemangioblastoma of the medulla was found on angiography. The patient's course and autopsy are described and the features of this disease are reviewed.

RÉSUMÉ: Un patient atteint de la maladie de Von Hippel-Landau fut suivi du moment où le diagnostic fut posé jusqu'au moment du décès 13 ans plus tard. Il était asymptomatique quand le diagnostic fut posé, quoique un hémangioblastome médullaire fut trouvé à l'angiographie. L'évolution de la maladie et l'autopsie du patient sont décrits et les particularités de cette maladie sont revues.

From the Departments of Neurology and Neurosurgery, University of California School of Medicine, San Francisco, California.

Reprint requests to Dr. Roger J. Porter, Applied Neurologic Research Branch, National Institute of Neurological and Communicative Disorders and Stroke, National Institutes of Health, Bethesda, Maryland 20014.
Von Hippel-Lindau's disease is a familial disorder presenting in young adult life with either visual symptoms due to the retinal hemangioblastoma (Von Hippel's tumor) or intermittent occipital headache, vertigo, and vomiting secondary to complications of the posterior fossa hemangioblastoma (Lindau's tumor). Associated visceral abnormalities include renal carcinoma or cysts, pancreatic cysts, and epididymal cysts and adenomas. This syndrome has been termed Lindau's disease by Cushing and Bailey (1928), and that eponym was used in the recent review of the subject by Grossman and Melmon (1972) who noted that it is also called Von Hippel -Lindau disease, central nervous system angiomatosis, hemangiomatosis, and angiomatosis of cerebellum and retinae.

Because there is little information available on the natural history of this disease, we present the following patient who was the first reported case in whom diagnosis preceded symptoms (Melmon and Rosen, 1964). During kindred screening, the patient was found to have an epididymal cystadenoma; angiography demonstrated an inoperable brainstem tumor. He subsequently developed complications of retinal and posterior fossa hemangioblastoma and died 13 years later.

Case report. An asymptomatic 39-year-old male plumber was first seen in 1961 as part of family screening examinations. The family history was strongly positive for Lindau's disease. The patient's mother died at age 33 from complications of cerebellar hemangioblastoma, and his only child was later found to have Lindau's disease as well. His past history was remarkable only for hospitalization because of syncope after a forced march in the Army and a duodenal ulcer in 1955. Physical findings included a psoriatic patch over the sternum and bilateral epididymal cysts. The retina of the right eye had an elevated fold with a tuft of neovascularization at the nasal margin of the optic disc; neither a tumor nodule nor the typical dilated, tortuous artery-vein pair was present. A mild right facial weakness and right extensor plantar response were present; the remainder of the neurologic examination was normal. An intravenous pyelogram showed slight lateral curving of the superior infundibulum of the left kidney, but bilateral renal angiography was normal. Epididymal biopsy revealed papillary cystadenoma. Lumbar puncture yielded fluid under a pressure of $190 \mathrm{~mm}$ of water, with $283 \mathrm{mg}$ percent protein. A pneumoencephalogram showed dilated ventricles and a posteriorly displaced vallecula. A diffuse $15 \times 20 \mathrm{~mm}$ midline blush in the medulla was most prominent in the capillary phase on vertebral angiography (Fig. 1). Radiation therapy of 4900 rads was delivered to a posterior fossa field over eight weeks. He remained asymptomatic and subsequent examinations showed flexor plantar responses.

Over a one-month period in 1967 the patient noted progressive blurring of vision in the right eye; visual acuity declined from $20 / 20$ to $20 / 100$. Increased vascularity and gliosis were present adjacent to the optic disc in the area previously noted to be abnormal, and several additional angiomata were noted. There was leakage of fluorescein from these new vessels. Several lesions were photocoagulated in both eyes and although visual acuity remained $20 / 15$ in the left eye, he could only count fingers at 5 feet with the right eye. An additional lesion in the right eye was photocoagulated in 1970 .

In January 1973, the patient developed a constant, bifrontal, throbbing headache which worsened over three weeks. He was hospitalized when examination revealed fine, horizontal left-beating nystagmus on left gaze and fresh hemorrhages near the optic discs compatible with early papilledema. Routine blood examination was normal except for a leukocytosis of 14,900 . The spinal fluid 


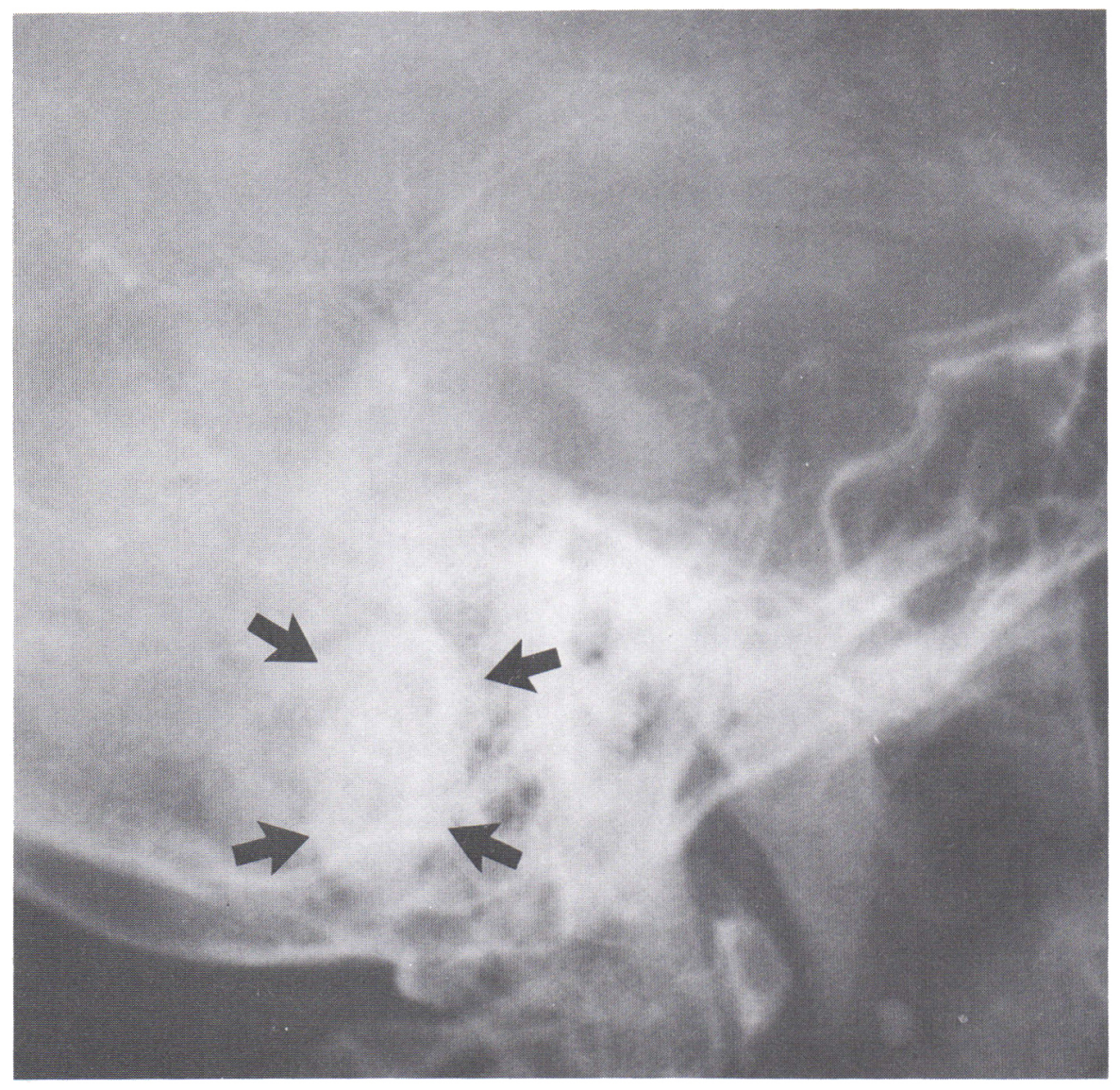

Figure 1-Lateral view of the vertebral angiogram shows the vascular tumor in the medulla oblongata in 1961 (arrows).

was clear with four red blood cells and no white cells; opening pressure was 160 $\mathrm{mm}$ and protein $236 \mathrm{mg}$ percent. Vertebral angiography disclosed a large vascular mass in the medulla and many new posterior fossa lesions (Fig. 2). The cervical cord was free of lesions. Carotid arteriograms showed dilated ventricles. Renal angiography demonstrated a highly vascular lesion in the middle third of the right kidney; on careful review of previous films, a small lesion in this area was present in 1961. By the seventh hospital day, papilledema had increased and the patient was started on dexamethasone, with some subsequent decrease in headache. On the ninth hospital day, a ventriculo-atrial shunt with a high pressure valve was placed. He underwent right radical nephrectomy one week later; the lesion was a renal cell carcinoma. He was discharged, and when seen in the clinic one month later, the papilledema had resolved and he had returned to work.

In August 1973 the patient developed headache, nausea, and vomiting. Examination findings were unchanged, except for slight unsteadiness on tandem gait. Arteriography showed normal ventricular size and good shunt placement. The vascular tumors were unchanged. His symptoms resolved spontaneously. At follow-up in December 1973, there was some incoordination of limbs, greater on the right and a shuffling, unsteadiness of gait. In early 1974 his condition remained unchanged. Visual acuity was 20/20 on the left and 20/200 on the right. In June 1974 the patient developed dysphagia and increasing ataxia. He subsequently died with a lobar pneumonia at another hospital.

\section{Necropsy findings}

The brain and spinal cord were provided by the hospital where the patient had died. On external appearance the convexities of the cerebral hemispheres were unremarkable with the exception of a shunt catheter in the right postcentral midconvexity area. The medulla was swollen irregularly. The right cerebellar tonsil was prominent, with a deep groove indicative of tonsillar herniation. The right cerebellar hemisphere was collapsed and flattened, and a slightly granular $4 \mathrm{~mm}$ reddish mass was present on the inferior surface of the leftcerebellar hemisphere. Coronal sections through the cerebral hemispheres revealed slight dilatation of the left lateral ventricle. Horizontal sections through the brainstem and cerebellum showed marked distortion of the tectum of the midbrain with distortion and compression of the collicular plate, especially on the right. The aqueduct was dilated throughout its length, with marked fourth ventricular enlargement. A large, multiloculated cyst measuring $4 \times 5 \times 3 \mathrm{~cm}$ in greatest dimension extended the entire length of the right cerebellar hemisphere. A $1 \mathrm{~cm}$ hemorrhagic, slightly firm mural nodule was found near the wall of the fourth ventricle at the inferior-posterior margin of the cyst (Fig. 3). Two additional well-circumscribed, small, granular, hemorrhagic tumor nodules were noted in the left cerebellar hemisphere. A large vascular tumor confined to the medullary velum occupied the roof of the fourth ventricle from the rostral medulla to the junction with cervical cord (Fig. 4).

A $2 \mathrm{~mm}$ circumscribed, white nodule was noted in the left dorsal aspect of the lumbar (L2) cord, which extended to the surface in the region of the entering posterior root. This nodule was contiguous with a small 1 to $2 \mathrm{~mm}$ cavity in the dorsal aspect of the cord.

\section{Microscopic examination}

Most of the tumor nodules were similar in microscopic appearance and were composed of a myriad of capillary-sized vessels that in most areas were collapsed and identifiable only by their flattened endothelial cells and staining for reticulin. Plump cells with foamy to granular cytoplasm and round to oval nuclei were occasionally crowded between these vascular channels. The tumors were extremely well circumscribed by a dense zone of gliosis, but were not encapsulated. The cerebellar cyst wall was composed of a dense band of astroglial fibers, but no malignant cells were seen. The medullary tumor was slightly differ- 
ent, with large zones replaced by hyaline-appearing collagen. The remainder of the tumor was similar to the other lesions. The dilated and distorted fourth ventricle showed loss of ependyma and replacement by dense gliosis. The central canal was not dilated in the upper cervical cord, and no syrinx was noted. Sections through the lumbar cord showed the dorsal white tumor mass to be composed of numerous capillary channels with occasional foamy or granular cells. The syrinx was distinct from the central canal and lined by dense gliosis.

The presence of cystadenoma of the pancreas, renal cell adenoma, and parathyroid adenoma was confirmed microscopically.

\section{DISCUSSION}

\section{Clinical symptoms and signs}

The average age at onset of symptoms in Lindau's disease is in the fourth decade, but the age range is 18 to 50 years, with a few exceptions (Grossman and Melmon, 1972). Our patient is fairly typical in that he first became symptomatic with visual complaints referable to the retinal lesions. Blurred vision, or occasionally eye pain, is the usual complaint. The symptoms and signs of Lindau's tumor as delineated by Olivecrona (1952), Cramer and Kimsey (1952), and Möller (1944) are listed in Table 1.

The most common symptom of Lindau's tumor is headache. It was the first symptom of central nervous system involvement in 84 percent of Olivecrona's large series of patients and was present in all patients at the time of hospital admission (Olivecrona, 1952). The headache was as often frontal or temporal as it was suboccipital in patients studied by Cramer and Kimsey (1952). It is often intermittent, as are the other symptoms of Lindau's tumor, but becomes progressively more severe. Vertigo and vomiting occurred soon after the onset of headache in many patients; Olivecrona pointed out that this triad of symptoms is a fairly reliable indication of a posterior fossa tumor. Cramer and Kimsey found tinnitus, usually associated with vertigo, in eight patients, four of whom
TABLE 1

Symptoms and Signs of Lindau's Disease

\begin{tabular}{ccc} 
& Percent of cases & \\
\hline $\begin{array}{c}\text { Olivecrona } \\
(1952)\end{array}$ & $\begin{array}{c}\text { Cramer \& Kimsey } \\
(1952)\end{array}$ & $\begin{array}{c}\text { Möller } \\
(1944)\end{array}$ \\
$\begin{array}{c}(70 \text { cases }) \\
\text { (48 cases) }\end{array}$ & (27 cases)
\end{tabular}

SYMPTOMS

Headache

Vertigo

Vomiting

Diplopia

Tinnitus

SIGNS

General

Stiff neck

"Cerebellar fits"

$\begin{array}{rrr}100 & 92 & - \\ 60 & 61 & - \\ 41 & 53 & - \\ 24 & \overline{17} & -\end{array}$

Cranial Nerves

Papilledema

Decreased visual acuity

Limitation of upward gaze

Lateral rectus palsy

Decreased corneal reflex

Facial hypesthesia

Facial weakness

Decreased hearing

Hoarseness

11

20

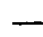

Cerebellar

Gait ataxia

Dysdiadochokinesia

Unsteady stance

Nystagmus

Dysmetria

$\begin{array}{rrr}90 & 84 & 74 \\ 27 & - & - \\ 10 & - & 30 \\ - & - & 22 \\ -14 & - & 7 \\ 21 & - & - \\ 3 & - & - \\ 3 & - & -\end{array}$

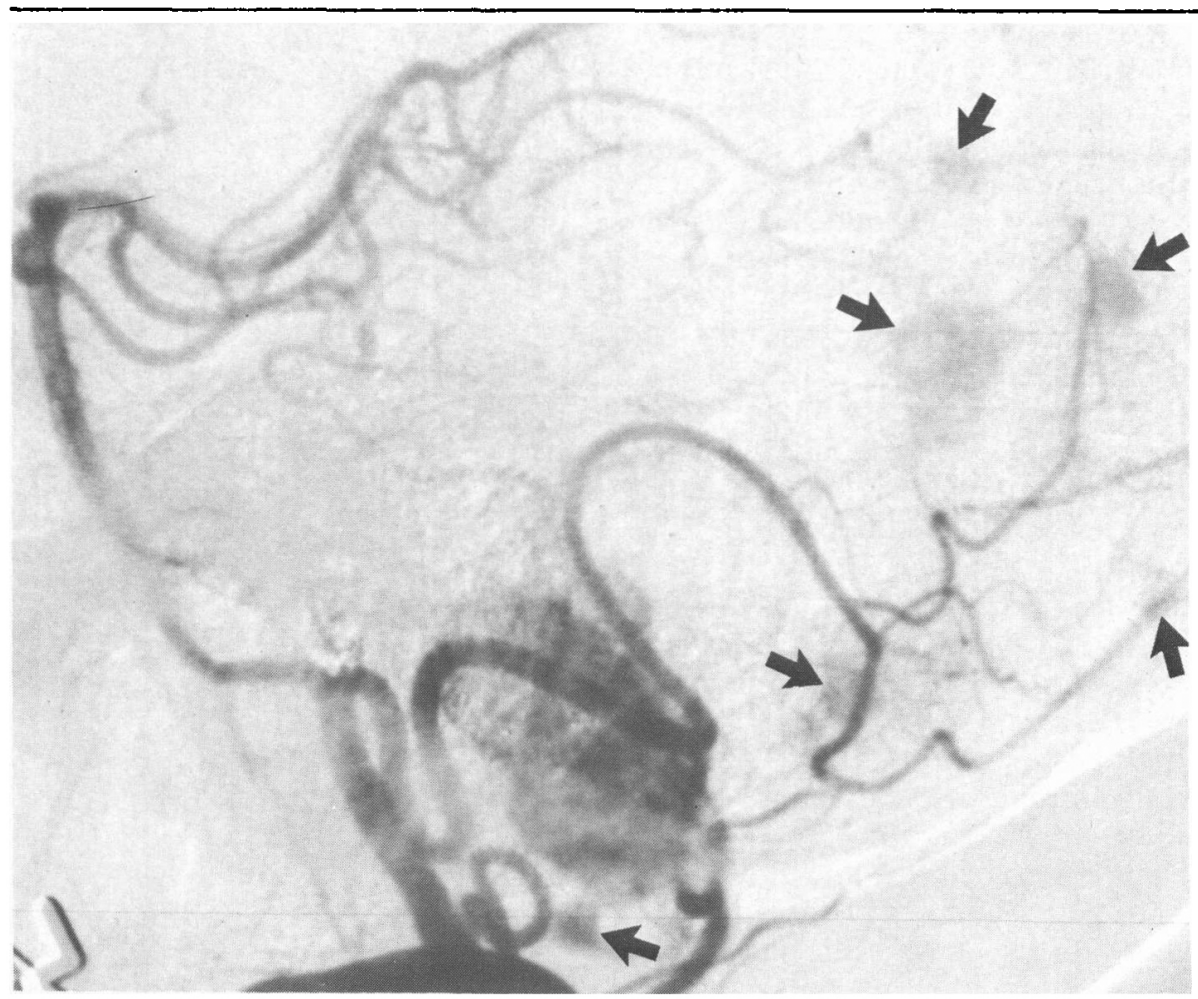

Figure 2-In addition to the large lesion in the medulla, which has increased in size since 1961, at least six additional lesions can be seen in 1973 (arrows). 
had evidence of brainstem and cranial nerve involvement with tumor. Diplopia and altered mentation have been reported; the latter probably reflects hydrocephalus.

Probably the most important physical sign, because of its great diagnostic significance, is the retinal hemangioblastoma. Funduscopic examination discloses a peripheral red spot associated with a dilated and tortuous retinal artery and vein, usually found on the temporal side of the retina near the equator (Welch, 1970). The retinal lesions are reported to be bilateral in 50 percent of patients, with a 20 percent incidence of associated Lindau's tumor (Keith, 1973). Cushing and Bailey (1928) emphasized the need for scrutiny of the peripheral retina in every patient with symptoms or signs of a cerebellar tumor. As shown in the table, papilledema is the most common sign of Lindau's tumor. Olivecrona attributed loss of visual acuity to papilledema of long duration in onethird of his patients. Erosion of posterior clinoids on skull roentgenograms, suggesting chronic intracranial hypertension, was seen in an equal number of patients. Lindau's tumor presumably causes a block in cerebrospinal fluid circulation, resulting in increased intracranial pressure and the associated clinical symptoms that bring the patient to a physician. Further, the syndrome of hydrocephalus may be intermittent, as illustrated by our patient and as commented on by Dandy (1928), as well as Cushing and Bailey (1928). Perlmutter and colleagues (1950) quoted Hughlings Jackson, commenting on one of his own cases, that the "most striking clinical feature was the remarkable intermission of the symptoms." Signs of cerebellar tonsillar herniation were seen in 20 percent of Olivecrona's patients, and neck stiffness, presumably reflecting early tonsillar herniation, was present in 11 percent (Olivecrona, 1952). Signs of cerebellar dysfunction were also quite common, with cranial nerve disturbances seen only occasionally. Facial weakness, when present, was usually ipsilateral to the tumor.
The evolution of the syndrome associated with Lindau's tumor is generally more rapid in younger patients, according to Olivecrona (1952). Two-thirds of his patients came under neurosurgical care within a year after appearance of the first symptom. Perlmutter and colleagues (1950) reported an average duration of symptoms of 10 months prior to hospitalization; the range was 3 weeks to 7 years. Our patient was hospitalized 1 month after the onset of headache.

\section{Laboratory observations}

Polycythemia was not observed in our patient, although it has been reported in 10 to 20 percent of patients with Lindau's disease (Melmon and Rosen, 1964). The very high cerebrospinal fluid protein of $283 \mathrm{mg}$ percent in 1961 is consistent with the elevation reported by others for hemangioblastoma of the medulla oblongata (Grossman and Melmon, 1972). Lumbar puncture must be viewed as a procedure with considerable hazard and minimal diagnostic value in the patient with Lindau's

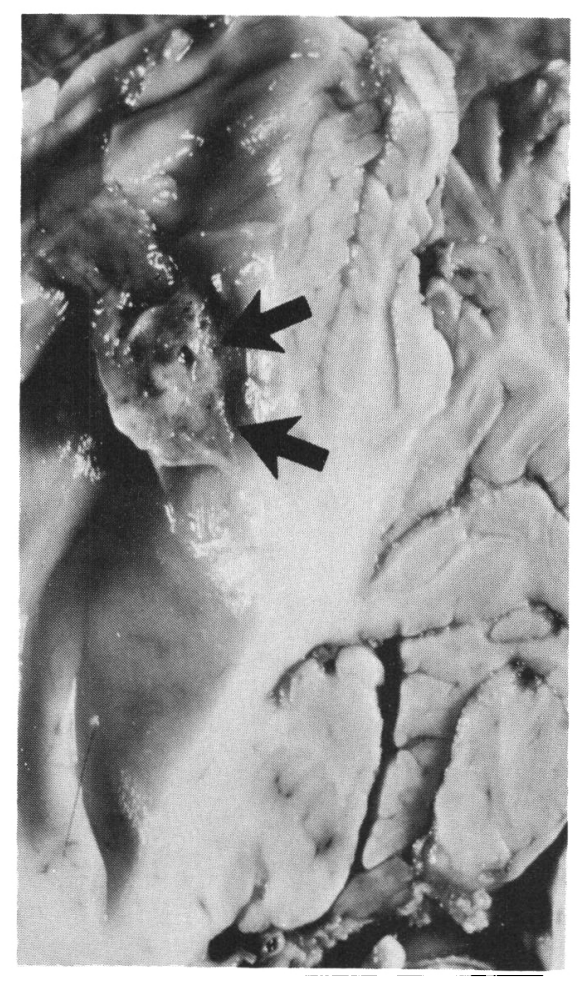

Figure 3-A smooth walled cyst in the right cerebellar hemisphere exhibits the mural nodule (arrows). tumor and increased intracranial pressure.

Evaluation should include intravenous pyelography because of the frequent association of renal cell carcinoma. Malek and Greene (1971) reported a high incidence of malignant change in the remaining kidney from 3 to 14 years after nephrectomy. As mentioned above, skull roentgenograms may show evidence of chronic intracranial hypertension. The hypercalcemia found in our patient may be secondary to the parathyroid adenoma.

With refined posterior fossa angiography, the vertebral arteriogram is probably the most helpful test, both for diagnosis of Lindau's tumor and for following its evolution. Ventricular size may be determined by carotid angiography. The angiography in this case, with a 12-year interval between studies, showed no change in the brainstem lesion and three new lesions in the cerebellum.

\section{Neuropathology}

The posterior fossa hemangioblastoma, or Lindau's tumor, is usually located in the cerebellum, often in the midline near the posterior end of the fourth ventricle (Cushing and Bailey, 1928). Lindau (1957) noted multiple tumors in 10 percent of his cases. The presence of a large asymptomatic lesion in the medulla oblongata, as in the present case, is quite unusual.

No medullary lesions were found in the eleven cases of Lindau's tumor reported by Cushing and Bailey (1928). Berblinger (1922) reported the first case of hemangioblastoma of the medulla in 1922. In 1936, Levin reviewed the sixteen reported cases of multiple hemangioblastomas of the central nervous system. Of these cases there was involvement of the pons and medulla oblongata in six. One case had an isolated large hemangioblastoma in the floor of the fourth ventricle. In 27 cases of Lindau's tumor, Möller (1944) found seven in the roof and three in the floor of the fourth ventricle. Of Olivecrona's seventy cases of Lindau's tumor, 56 were in the cerebellar hemispheres, 9 in the vermis, and 5 in the region of the 
fourth ventricle (Olivecrona, 1952). A few of the latter involved the posterior medullary velum, but there was great variability of location. In our patient, the tumor was located in the floor of the fourth ventricle. It is apparent that Lindau's tumor occasionally involves the brainstem, with a tendency to occur in structures that surround the fourth ventricle.

Spinal cord hemangioblastoma is part of Lindau's disease. Its incidence is uncertain because the spinal cord is often not examined postmortem, and the tumor is often asymptomatic, as in the present case. Levin (1936) reported that examination of the spinal cord in ten cases of Lindau's disease revealed one or more tumors in the cord substance or in the nerve roots. The lesions are usually located in the dorsal columns at the cervico-thoracic or thoracolumbar junctions of the cord. A syrinx often extends up or down from the tumor or may occur at a distance from it. Wyburn-Mason (1943) found syringomyelia in 77 percent of 26 cases and termed it an integral part of Lindau's complex.

We are not aware of any previous instance of associated parathyroid adenoma in Lindau's disease. Because of its possible relationship to the nephrectomy, we are uncertain of its significance in our patient.

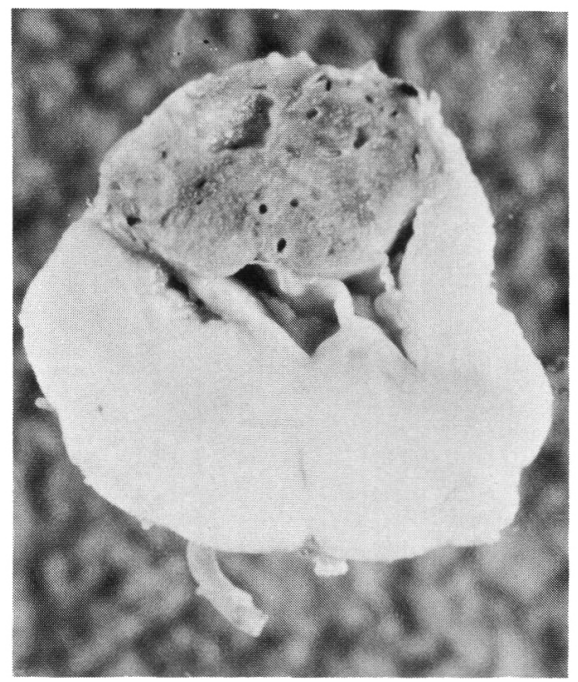

Figure 4-The vascular tumor is shown arising from the dorsal medullary velum, with adjacent slit-like cavities that are clearly separate from the fourth ventricle.

\section{Therapy}

Radiotherapy has been used to treat inoperable brainstem lesions, with variable results (Hirschfeld, 1944; Isaac et al., 1956; Brody and Rodriquez, 1961). Interpretation of results from radiation therapy is especially difficult due to the variable course of the lesions themselves. There is one recent report of a retinal lesion, treated only with corticosteroids for an associated uveitis, in which there was no progression over a 10-year period (Keith, 1973). Similarly, it is difficult to determine the effect of radiation therapy in the present case where there was no progression of the hemangioblastoma of the medulla oblongata over a 12-year period. The treatment of symptomatic cerebellar lesions is surgical removal, with an operative mortality rate of about 10 percent. Many patients are alive and well many years after surgery (Perlmutter et al, 1950).

\section{CONCLUSION}

The typical protean nature of the disease process and its inexorable course are well illustrated in this patient. Discovery of an epididymal cystadenoma during kindred screening led to the diagnosis. The vascular lesions in the retina and posterior fossa were then followed from their incipient phase until they became symptomatic, 6 and 12 years later, respectively. The importance of early diagnosis is also well illustrated. Early diagnosis facilitated appropriate forms of therapy as the various lesions and their complications emerged. The affected daughter of our patient was born prior to his diagnosis; early diagnosis and genetic counseling may prevent such tragedies. Whenever the diagnosis is made, complete screening and close, long-term surveillance are essential for the control of Lindau's disease.

\section{ACKNOWLEDGMENT}

We are grateful to Dr. Hans Newton for reviewing the roentgenographs and to $\mathrm{Dr}$ Jerry Wolinsky for reviewing the manuscript.

\section{REFERENCES}

BERBLINGER, W. (1922). Zur Auffassung von der sogenannten v. Hippelschen Krankheit der Netzhaut: Capilläres Hämangiom im verlängerten Mark. Albrecht von Graefes Arch. Ophthalmol. 110: 395-413.

BRODY, J. I., and RODRIQUEZ, F. (1961). Cerebellar hemangioblastoma and polycythemia (erythrocythemia). Am. J. Med. Sci. 242: 579-584.

CRAMER, F. and KIMSEY, W. (1952). The cerebellar hemangioblastomas: Review of fifty-three cases, with special reference to cerebellar cysts and the association of polycythemia. Arch. Neurol. Psychiatry 67: $237-252$.

CUSHING, $H$. and BAILEY, P. (1928). Tumors Arising from Blood-vessels of the Brain: Angiomatous Malformations and Hemangioblastomas; Springfield, Ill., Charles C. Thomas, pp. 119-217.

DANDY, W. E. (1928). Venous abnormalities and angiomas of the brain. Arch. Surg. 17: 715-793.

GROSSMAN, M. and MELMON, K. L. (1972). Von Hippel-Lindau disease. In Vinken, P.J., Bruyn G. W. (Editors): Handbook of Clinical Neurology, Vol. 14. Amsterdam, North-Holland, pp. 241-259.

HIRSCHFELD, M. H. (1944). Hemangioblastoma of the medulla - Lindau's disease: Response to radiation therapy. J. Nerv. Ment. Dis. 99: 656-659.

ISAAC, F., SCHOEN, I. and WALKER, P. (1956). An unusual case of Lindau's disease: Cystic disease of the kidneys and pancreas with renal and cerebellar tumors. Am. J. Roentgenol. 75: 912-920.

KEITH, C. G. (1973). Angiomatosis retinae. Br. J. Ophthalmol. 57: 593-594.

LEVIN, P. M. (1936). Multiple hereditary hemangioblastomas of the nervous system. Arch. Neurol. Psychiatry, 36: 384-391.

LINDAU, A. (1957). Capillary angiomatosis of the central nervous system. Acta Genet. (Basel) 7: 338-340.

MALEK, R. S. and GREENE, L. F. (1971). Urologic aspects of Hippel-Lindau syndrome. J. Urol. 106: 800-801.

MELMON, K. L. and ROSEN, S. W. (1964). Lindau's disease: Review of the literature and study of a large kindred. Am. J. Med. 36: 595-617.

MÖLLER, H. U. (1944). Ophthalmic symptoms and heredity in cerebellar angioreticuloma. Acta Psychiatr. Neurol. 19: 275-292.

OLIVECRONA, H. (1952). The cerebellar angioreticulomas. J. Neurosurg. 9: 317-330.

PERLMUTTER, I., HORRAX, G. and POP. PEN, J. L. (1950). Cystic hemangioblastomas of the cerebellum. End results in 25 verified cases. Surg. Gynecol. Obstet. 91: 88-89.

WELCH, R. B. (1970). Von Hippel-Lindau disease: The recognition and treatment of early angiomatosis retinae and the use of cryosurgery as an adjunct to therapy. Trans. Am. Ophthalmol. Soc. 68: 367-424.

WYBURN-MASON, R. (1943). The Vascular Abnormalities and Tumors of the Spinal Cord and its Membranes. St. Louis, Mo., C. V. Mosby, pp. 60-84. 